\title{
Area factors and suicide: 5-year follow-up of the Northern Ireland population
}

\author{
Dermot O'Reilly, Michael Rosato, Sheelah Connolly and Chris Cardwell
}

\section{Background}

Suicide rates vary markedly between areas but it is unclear whether this is due to differences in population composition or to contextual factors operating at an area level.

\section{Aims}

To determine if area factors are independently related to suicide risk after adjustment for individual and family characteristics.

\section{Method}

A 5-year record linkage study was conducted of 1116748 non-institutionalised individuals aged 16-74 years, enumerated at the 2001 Northern Ireland census.

\section{Results}

The cohort experienced 566 suicides during follow-up. Suicide risks were lowest for women and for those who were married or cohabiting. Indicators of individual and household disadvantage and economic and health status at the time of the census were also strongly related to risk of suicide. The higher rates of suicide in the more deprived and socially fragmented areas disappeared after adjustment for individual and household factors. There was no significant relationship between population density and risk of suicide.

\section{Conclusions}

Differences in rates of suicide between areas are predominantly due to population characteristics rather than to area-level factors, which suggests that policies targeted at area-level factors are unlikely to significantly influence suicides rates.

\section{Declaration of interest}

None.
Research shows that suicide risk is related to both individual and household characteristics such as age, gender, marital status and socio-economic circumstances: it is less clear whether area of residence constitutes an additional, independent risk. Previous work has demonstrated higher prevalence of social problems, mental disorder and suicidal behaviour in inner cities ${ }^{1,2}$ and higher suicide rates in deprived or socially fragmented areas. ${ }^{3}$ Whitley et al also showed that suicide rates increased most in areas that recorded the largest increases in deprivation or social fragmentation over time. ${ }^{4}$ However, such studies cannot determine whether these are area effects (context) or due to the characteristics of the people living in these areas (composition). Such findings need to be confirmed using longitudinal data that include both individual and area characteristics. We report on such a study, based on a 5-year follow-up of the entire Northern Ireland population enumerated in the 2001 census.

\section{Method}

In 2006 the Northern Ireland Statistics and Research Agency (NISRA) undertook an exercise to link all those enumerated at the Northern Ireland 2001 census to deaths to residents in the subsequent 5 years. This formed a 5-year longitudinal study of the whole enumerated population, linking $94 \%$ of all deaths occurring over this period. Details of the linkage process are described elsewhere. ${ }^{5}$ These data were anonymised, held in a safe setting by NISRA and made available to the research team for this study. In keeping with established practice both definite suicides and deaths of undetermined intent were combined to define suicide (ICD-10 codes X60-X84, Y10-Y34, Y87.0), ${ }^{6}$ reducing the possible effects of misclassification. The analysis was limited to enumerated individuals aged 16-74 years at the time of the census: this allowed socio-economic factors, which in the 2001 UK census were coded only for those less than 75 years old, to be applied to the whole of the analysis population. A total of 12055 individuals living in communal establishments (such as nursing or residential homes, hospitals and prisons) were also excluded from the analysis as they would be little influenced by area-level factors. Eight suicides (or $1.4 \%$ of all suicides occurring over the study period) were recorded for this excluded group. The resulting cohort available for analysis comprised 1116748 individuals.

\section{Individual and household characteristics}

All attributes of the cohort members were as described on the census record. Marital status (categorised as married or cohabiting; never married or single; separated or divorced; and widowed) and household size (the number of people of any age living at the address) were included as individual-level measures of social support. Because initial analysis showed excess risk of suicide in single-person households but no difference in risk between households with two or more residents, a binary household size indicator was generated (single-person households, households with two or more people). Socio-economic status was assessed using housing tenure (categorised as owner-occupied, private renting or social renting); car availability (two or more cars, one car or no car) and social class using the National Statistics Socioeconomic Classification. ${ }^{7}$ These were then combined to derive a single measure of relative material disadvantage comprising eight categories ranked from the least deprived group (professional owner-occupiers with access to at least two cars), to the most deprived (unemployed people living in socially rented accommodation with no car access). Economic activity, known to be independently associated with suicide, was also included. ${ }^{8-11}$ The two census questions on self-reported health status were also included: one asked about the presence of a limiting long-term illness and required a 'yes/no' response; the other, on general health in the year preceding the census, offered three responses - 'good', 'fairly good' and 'not good'. 


\section{Area characteristics}

Three indicators relating to area of residence were derived at census super-output area level (a standard government administrative area, with average population size 1894): material deprivation, population density and social fragmentation. Material deprivation was defined as the proportion in the super-output area in receipt of means-tested social security benefits. ${ }^{12}$ Population density was measured as the census population divided by the area, in $\mathrm{km}^{2}$; this was included as a proxy for the urban-rural character of the area of residence. Following seminal work by Congdon ${ }^{3}$ and Whitley et $a l^{4}$ a measure of social fragmentation was constructed using four census variables: the percentage of people in private rented accommodation; the percentage of the adult population who were unmarried; the percentage of the population aged less than 65 years who were living alone; and the percentage population turnover in the year preceding the census. The fragmentation score was an unweighted sum of the standardised levels of these variables, giving a mean of 0.00 (s.d.=3.27). These areas were then ranked (separately) for each set of area characteristics and split into quintiles containing approximately equal proportions of the population.

\section{Statistical methods}

The relationship between cohort characteristics and death due to suicide was investigated using Cox proportional hazards modelling. Likelihood ratio statistics were used to test for differences in hazard rates between categories and trends across categories. Analysis was undertaken in two stages: the first to build a model that best described the individual and household factors associated with increased suicide risk, and the second to determine whether or not the area characteristics contributed to suicide risk independent of these. The Cox proportional hazard model assumes the independence of individual responses, an assumption that might not hold if responses within an area were correlated. Any such clustering within areas could exaggerate the precision with which associations are estimated. Sensitivity analyses were conducted using generalised estimating equation models to account for any within-area clustering. ${ }^{13}$ Generalised estimating equation logistic regression population average models were used to make inferences concerning area characteristics. ${ }^{14}$ Logistic regression models were used to conduct these sensitivity analyses, both for simplicity and because the estimates from the final Cox proportional hazard model were similar to estimates from a corresponding logistic regression model.

\section{Results}

In the 5 years of follow-up 566 deaths were registered as either suicide or of 'undetermined intent': $425(75.1 \%)$ deaths were of men and $75.3 \%$ were of people aged less than 55 years at the time of census.

\section{Individual and household-level indicators of suicide risk}

Female suicide risk was about a third that of males (hazard ratio $(\mathrm{HR})=0.30,95 \%$ CI $0.24-0.37)$. Table 1 shows the relationship between suicide and individual and household factors. After adjustment for age and gender, those currently married or cohabiting at the time of census showed the lowest risks compared with all other marital status categories, with the excess risk associated with the single/never married and separated/divorced categories being maintained even after inclusion of the other demographic and socio-economic factors. Those living alone were associated with higher suicide risk even after adjustment for age, gender and marital status (HR=1.53, 95\% CI 1.18-1.99), although further adjustment for socio-economic and general health status weakened this association considerably ( $\mathrm{HR}=1.28,95 \%$ CI $0.98-$ $1.67 ; P=0.073$ ).

There was a strong correlation between economic activity and deprivation, so mutual adjustment generally attenuated the effects of each. Among the economic activity categories those who were permanently ill had the highest suicide risks, with a four-fold excess after adjustment for age, gender, marital status and household size (despite constituting only $9.0 \%$ of the cohort they accounted for $25.3 \%$ of suicides). However, about half of this excess risk was explained by adjustment for disadvantage and health status. People defined as either 'homemakers' (90.6\% of whom were female) or 'other economically inactive' had a $60 \%$ excess suicide risk when compared with those in employment. After adjustment for age, gender, marital status and household composition, unemployed people had a $68 \%$ excess suicide risk when compared with employed people (HR $=1.68$, 95\% CI 1.20 2.35). However, further adjustment for measures of deprivation and baseline health status reduced this to a $28 \%$ excess (HR $=1.28,95 \%$ CI $0.89-1.84)$. There was a strong and graded relationship between individual and household deprivation and risk of suicide, although this was somewhat attenuated by the addition of health factors in the modelling. Poorer health status at the time of census, whether measured in terms of long-term illness or general health, was also strongly associated with higher suicide risk. However, when both self-reported health measures were simultaneously included in a model 'general health' remained significant whereas 'limiting long-term illness' became non-significant (likelihood ratio test $P<0.05$ ). For reasons of parsimony, therefore, long-term illness was not included in the final presented analysis.

\section{Area-level indicators of suicide risk}

Despite the equal distribution of population across quintiles, the more fragmented and deprived areas contributed a disproportionate number of suicides (Table 2). This is reflected in the increasing gradient of HRs in the age- and gender-adjusted models. (Note: when using the logistic regression generalised estimating equation models that allowed adjustment for individual-level covariates and clustering within areas, the area-level estimates of association and corresponding significance levels were little altered from those presented in Table 2 and have not been shown.) After further adjustment for the individual and household factors (marital status, household composition, socio-economic and employment status, and baseline health status) the association between suicide risk and area deprivation and levels of social fragmentation disappeared. Patterns associated with population density appeared slightly more complex: although the model adjusted for age and gender showed some indication of higher risk for those in the least and most densely populated quintiles when compared with the central quintiles, this disappeared in the fully adjusted model, which showed only weak evidence of an effect associated with the least densely populated quintile.

\section{Discussion}

With a cohort of more than 1 million community residents, this is one of the largest longitudinal studies of suicide risk undertaken in the UK. It has generally confirmed the known associations between suicide and indicators of isolation and socio-economic disadvantage at both individual and household level. Married or 
cohabiting individuals had the lowest risk, compared with both single/never married and the separated/divorced categories. The analysis suggests that at least some of this excess is due to socioeconomic disadvantage. Household composition is a factor that is not usually examined as separate from marital status, and although the increased risk associated with single-person households was non-significant in the fully adjusted model, its importance as an indication of a developing social trend suggests that it should be included in future studies. The non-significant excess risk of suicide among the unemployed requires some explanation: until fairly recently Northern Ireland consistently had the highest rates of unemployment, long-term unemployment and proportions of the working-age population defined as economically inactive of any region of the UK, and in such circumstances, where future employment chances are slim, it is thought that many of those who might otherwise register as unemployed choose to register as economically inactive owing to chronic ill health. ${ }^{8}$ This therefore may displace some of the effect of unemployment to those defined as permanently ill. Of the two self-reported morbidity measures, only general health in the previous year was significantly related to suicide risk; limiting long-term illness was not. This may be because long-term illness primarily reflects physical aspects of health status, whereas general health, being a less specific measure, may be more sensitive to psychiatric morbidity.

\section{Area characteristics and comparison with other studies}

The study showed that, after controlling for individual and household characteristics, area of residence did not exert an independent influence on suicide risk, suggesting that variation in suicide rates between areas is explained by differences between the types of people living in these areas. This can be seen as contrasting with some findings from recent ecological studies in Great Britain and other high-income countries, and can imply that some shift of emphasis in policy may be appropriate. For example, Congdon, Whitley et al and Gunnell et al have shown strong associations between rates of suicide and self-harm and levels of deprivation or social fragmentation, ${ }^{3,4,15}$ factors that have also

\begin{tabular}{|c|c|c|c|c|c|}
\hline \multirow[b]{2}{*}{ Individual and household factors } & \multirow{2}{*}{$\begin{array}{l}\text { Proportion of population } \\
\text { (number of suicides) \% ( } n \text { ) }\end{array}$} & \multicolumn{2}{|c|}{ Adjusted for age and gender } & \multicolumn{2}{|c|}{ Fully adjusted $^{\mathrm{a}}$} \\
\hline & & $\mathrm{HR}(95 \% \mathrm{Cl})$ & $P$ & $\mathrm{HR}(95 \% \mathrm{Cl})$ & $P$ \\
\hline \multicolumn{6}{|l|}{ Age, years } \\
\hline $16-24$ & $17.2(97)$ & 1.00 (Reference) & \multirow{6}{*}{$\begin{array}{l}<0.001 \\
(<0.019)^{\mathrm{b}}\end{array}$} & 1.00 (Reference) & \multirow{6}{*}{$\begin{array}{l}<0.001 \\
(<0.001)^{\mathrm{b}}\end{array}$} \\
\hline $25-34$ & $20.0(119)$ & $1.08(0.83-1.41)$ & & $0.90(0.66-1.23)$ & \\
\hline $35-44$ & $21.0(144)$ & $1.24(0.96-1.60)$ & & $0.97(0.70-1.35)$ & \\
\hline $45-54$ & $17.2(114)$ & $1.19(0.91-1.56)$ & & $0.82(0.57-1.17)$ & \\
\hline $55-64$ & $14.1(65)$ & $0.85(0.62-1.16)$ & & $0.46(0.31-0.70)$ & \\
\hline $65-74$ & $10.6(27)$ & $0.51(0.33-0.78)$ & & $0.29(0.16-0.53)$ & \\
\hline \multicolumn{6}{|l|}{ Gender } \\
\hline Male & $48.5(425)$ & 1.00 (Reference) & \multirow{2}{*}{$<0.001$} & 1.00 (Reference) & \multirow[t]{2}{*}{$<0.001$} \\
\hline Female & $51.5(141)$ & $0.31(0.26-0.38)$ & & $0.30(0.24-0.37)$ & \\
\hline \multicolumn{6}{|l|}{ Marital status } \\
\hline Married/cohabiting & $58.8(254)$ & 1.00 (Reference) & \multirow[t]{4}{*}{$<0.001$} & 1.00 (Reference) & \multirow[t]{4}{*}{0.006} \\
\hline Single & $30.2(222)$ & $1.96(1.57-2.44)$ & & $1.41(1.10-1.80)$ & \\
\hline Separated/divorced & $6.9(77)$ & $2.89(2.24-3.74)$ & & $1.67(1.22-2.26)$ & \\
\hline Widowed & $4.1(13)$ & $1.52(0.85-2.72)$ & & $1.07(0.59-1.95)$ & \\
\hline \multicolumn{6}{|l|}{ Household size } \\
\hline Two or more persons & $89.5(453)$ & 1.00 (Reference) & \multirow[t]{2}{*}{$<0.001$} & 1.00 (Reference) & \multirow[t]{2}{*}{0.08} \\
\hline One person & $10.5(113)$ & $2.38(1.93-2.94)$ & & $1.28(0.98-1.67)$ & \\
\hline \multicolumn{6}{|l|}{ Economic activity } \\
\hline Employed & $56.2(254)$ & 1.00 (Reference) & \multirow[t]{7}{*}{$<0.001$} & 1.00 (Reference) & \multirow[t]{7}{*}{$<0.001$} \\
\hline Unemployed & $4.0(41)$ & $1.95(1.40-2.72)$ & & $1.28(0.89-1.84)$ & \\
\hline Student & $7.8(25)$ & $0.65(0.41-1.02)$ & & $1.19(0.17-8.59)$ & \\
\hline Retired & $11.3(30)$ & $1.91(1.16-3.14)$ & & $1.38(0.82-2.33)$ & \\
\hline Homemaker & $7.5(36)$ & $2.11(1.46-3.04)$ & & $1.65(1.12-2.41)$ & \\
\hline Permanently ill & $9.0(143)$ & $4.80(3.88-5.95)$ & & $2.44(1.81-3.29)$ & \\
\hline Other economically inactive & $4.2(37)$ & $2.65(1.89-3.74)$ & & $1.63(1.12-2.38)$ & \\
\hline \multicolumn{6}{|l|}{ Deprivation category } \\
\hline Least deprived & $14.6(39)$ & 1.00 (Reference) & \multirow{8}{*}{$\begin{array}{l}<0.001 \\
(<0.001)^{\mathrm{b}}\end{array}$} & 1.00 (Reference) & \multirow{8}{*}{$\begin{array}{l}<0.001 \\
(<0.001)^{b}\end{array}$} \\
\hline Second & $20.4(83)$ & $1.57(1.07-2.29)$ & & $1.31(0.89-1.92)$ & \\
\hline Third & $21.6(94)$ & $1.71(1.17-2.49)$ & & $1.30(0.89-1.90)$ & \\
\hline Fourth & $19.6(117)$ & $2.46(1.71-3.53)$ & & $1.67(1.15-2.43)$ & \\
\hline Fifth & $8.4(55)$ & $2.92(1.93-4.41)$ & & $1.50(0.97-2.32)$ & \\
\hline Sixth & $6.8(62)$ & $3.98(2.66-5.95)$ & & $1.81(1.17-2.78)$ & \\
\hline Seventh & $6.7(67)$ & $4.62(3.11-6.89)$ & & $1.85(1.19-2.86)$ & \\
\hline Most deprived & $1.9(25)$ & $5.68(3.43-9.40)$ & & $1.92(1.08-3.39)$ & \\
\hline \multicolumn{6}{|l|}{ General health } \\
\hline Good & $66.9(272)$ & 1.00 (Reference) & \multirow{3}{*}{$\begin{array}{l}<0.001 \\
(<0.001)^{b}\end{array}$} & 1.00 (Reference) & \multirow{3}{*}{$\begin{array}{l}<0.001 \\
(<0.001)^{b}\end{array}$} \\
\hline Fair & $21.3(144)$ & $2.17(1.77-2.66)$ & & $1.62(1.30-2.07)$ & \\
\hline Not good & $11.8(140)$ & $3.98(3.21-4.93)$ & & $1.86(1.39-2.49)$ & \\
\hline $\begin{array}{l}\text { HR, hazard ratio. } \\
\text { a. Adjusted for other variables in table. } \\
\text { b. Value for test of linear trend across ca }\end{array}$ & & & & & \\
\hline
\end{tabular}




\begin{tabular}{|c|c|c|c|c|c|}
\hline \multirow[b]{2}{*}{ Area measures (in fifths) } & \multirow{2}{*}{$\begin{array}{l}\text { Proportion of population } \\
\text { (number of suicides) } \%(n)\end{array}$} & \multicolumn{2}{|c|}{ Adjusted for age and gender } & \multicolumn{2}{|c|}{ Fully adjusted ${ }^{a}$} \\
\hline & & $\mathrm{HR}(95 \% \mathrm{Cl})$ & $P$ & $\mathrm{HR}(95 \% \mathrm{Cl})$ & $P$ \\
\hline \multicolumn{6}{|l|}{ Area deprivation } \\
\hline Least deprived & $20.5(86)$ & 1.00 (Reference) & $<0.001$ & 1.00 (Reference) & 0.40 \\
\hline Second & $20.5(92)$ & $1.08(0.81-1.48)$ & & $0.88(0.65-1.19)$ & \\
\hline Third & $20.0(118)$ & $1.45(1.09-1.90)$ & & $1.01(0.76-1.36)$ & \\
\hline Fourth & $19.9(132)$ & $1.63(1.25-2.14)$ & & $0.97(0.72-1.29)$ & \\
\hline Most deprived & $19.1(138)$ & $1.79(1.37-2.34)$ & & $0.80(0.59-1.09)$ & \\
\hline Probability for trend & & & $<0.001$ & & 0.29 \\
\hline \multicolumn{6}{|l|}{ Social fragmentation } \\
\hline Least fragmented & $20.6(99)$ & 1.00 (Reference) & 0.021 & 1.00 (Reference) & 0.54 \\
\hline Second & $20.3(99)$ & $1.06(0.80-1.39)$ & & $0.86(0.65-1.15)$ & \\
\hline Third & $20.0(120)$ & $1.27(0.97-1.65)$ & & $0.97(0.73-1.28)$ & \\
\hline Fourth & $19.8(116)$ & $1.26(0.97-1.65)$ & & $0.81(0.61-1.08)$ & \\
\hline Most fragmented & $19.3(132)$ & 1.49 (1.17-1.93) & & $0.85(0.64-1.13)$ & \\
\hline Probability for trend & & & $<0.001$ & & 0.26 \\
\hline \multicolumn{6}{|l|}{ Population density } \\
\hline Least dense & $19.9(124)$ & 1.00 (Reference) & 0.25 & 1.00 (Reference) & 0.49 \\
\hline Second & $20.2(97)$ & $0.82(0.63-1.06)$ & & $0.81(0.62-1.07)$ & \\
\hline Third & $20.1(104)$ & $0.86(0.66-1.12)$ & & $0.84(0.65-1.10)$ & \\
\hline Fourth & $20.1(120)$ & $1.01(0.78-1.29)$ & & $0.92(0.72-1.20)$ & \\
\hline Most dense & $19.7(121)$ & $1.05(0.82-1.35)$ & & $0.83(0.64-1.08)$ & \\
\hline Probability for trend & & & 0.31 & & 0.07 \\
\hline \multicolumn{6}{|c|}{$\begin{array}{l}\text { HR, hazard ratio. } \\
\text { a. Deprivation and social fragmentation adjusted for age, gender, marital status, economic position, household size, and deprivation and health status. Population density adjusted for } \\
\text { age, gender, marital status, economic position, social class, health status and household size; household tenure and car availability not included as these have been shown to have } \\
\text { different relationships to disadvantage in urban and rural areas. }{ }^{39}\end{array}$} \\
\hline
\end{tabular}

been associated by Allardyce et al with increased rates of admission for first episodes of psychosis in Scotland. ${ }^{16}$ In the USA, Almog et al and Curtis et al have demonstrated higher rates of admission to psychiatric hospitals in New York from areas that were more deprived or that had higher levels of social fragmentation, ${ }^{17,18}$ and Hempstead showed that suicides in New Jersey tended to be higher in areas characterised by low population density and a higher proportion of single-person families, whereas non-fatal injuries were more closely related to indicators of deprivation. ${ }^{19}$ Fernquist \& Cutright showed that rates of suicide in 21 high-income countries throughout the world were strongly associated with a range of indicators of societal integration. ${ }^{20}$ However, ecological studies cannot determine if the variation between areas is due to concentrations of at-risk individuals in these areas. To do this requires studies that can examine the influence of area-level factors while simultaneously adjusting for individual-level factors. There have been relatively few such studies to date and none in the UK that has examined suicide. Reijneveld \& Schene in a secondary analysis of Amsterdam residents showed that the higher prevalence of mental disorders (as assessed by the 12-item General Health Questionnaire) in deprived areas was explained by the higher concentration of deprived people in these areas, ${ }^{21}$ and an analysis of the British Household Panel Study reported only a weak association between aggregate measures of deprivation and measures of mental health (also assessed using the General Health Questionnaire) after adjustment for individual measures. ${ }^{22}$ On the other hand, an analysis of Welsh Health Survey data by Skapinakis et al found a significant, if small, regional effect on mental health (measured using the mental health index of the 36-item Short Form Health Survey), explaining less than $1 \%$ of the total variance. ${ }^{24}$

To date there has been no other longitudinal study in the UK that has included both individual and area characteristics and that has had suicide as the end point. Hawton et al followed up patients in an ecological study relating rates of self-harm with deprivation and social fragmentation in Oxford to show that their characteristics were generally in keeping with those of the areas in which they lived, ${ }^{24}$ and Johnston et al, in a prospective analysis of self-harm in Manchester, showed that there was no association between area-level indicators of deprivation or social fragmentation and the risk of repetition of self-harm after adjustment for individual factors. ${ }^{25}$ It is difficult, however, to extrapolate from these studies, because it is recognised that the epidemiologies of self-harm and suicide are quite distinct. ${ }^{19}$ There have been two nested case-control studies based on the Danish longitudinal registries that looked at variations in suicide risk between areas while adjusting for individual factors. The first showed a higher suicide risk in urban areas among women but a lower risk for men, i.e. that the area characteristics had different effects on different subgroups of the population. ${ }^{26}$ The second study showed that the increased risk of suicide in poorer areas was greatly attenuated by controlling for differences in the people within these areas, and the study's authors concluded that the ecological associations were primarily due to the proportions of high-risk individuals living in particular areas. ${ }^{27}$ Martikainen et al, in a large study of 13589 suicides in Finland between 1991 and 2002, found that although the area effects were greatly reduced by adjustment for individual factors, they remained significant and were more important for men than for women and for alcohol-related rather than for non-alcohol-related suicides. ${ }^{28}$

\section{Methodological issues}

This study has some methodological considerations that require comment. The initial cohort was large enough to allow sufficient events to accrue in a relatively short time, reducing the likelihood that the attributes of cohort members would change over the follow-up period. Other studies have had to aggregate up to 10 or more years of data to obtain numbers of events sufficient to analyse. ${ }^{29}$ Excluding people resident in communal establishments from the analysis would also have increased the chances of demonstrating a significant area-level effect if one truly existed. On the other hand, our study was not sufficiently large to confidently examine variation by age and gender, and although we 
formally tested and found no significant interaction between these and the area factors, the study lacked sufficient power for us to be confident that none truly existed.

Although the study was based on data from the 2001 census and the General Registrar's mortality records, $6.0 \%$ of all deaths could not be linked to a census record. This can arise if either the dead person was not enumerated or difficulties arise in matching death records to corresponding census forms. Although not often reported, this is a limitation on all record linkage studies, with the notable exception of those in Scandinavian countries where universal population registration systems are the norm and an almost $100 \%$ linkage is regularly achieved. It is not clear whether the non-linkage of this small proportion of deaths leads to bias (or its directionality), as separate analysis has shown the phenomenon to be more common in young adults (especially males), the unmarried and those living in the most deprived areas. ${ }^{5}$ Weich \& Lewis have suggested that this might explain the generally weaker relationship between poverty and mental ill health found in longitudinal studies compared with cross-sectional studies. ${ }^{30}$ The area-level unit of analysis can be another significant source of variation and it is recognised that there can be difficulty in choosing an appropriate geographical unit to define community or neighbourhood, neither of which are likely to equate to routine administrative areas such as electoral wards. ${ }^{22}$ Additionally, in studies in which a significant area effect has been demonstrated, the effect sizes have been small, ${ }^{23}$ and may vary according to the size of the selected area unit. Kunce \& Anderson, discussing the 'contrariness' in the findings of ecological studies related to suicides, suggest that studies employing large aggregates of the population tend to bolster contextual influences on suicide, ${ }^{31}$ whereas data gathered on smaller aggregates yield little or weakened support for Durkheim's societal factors. ${ }^{32}$ The area-level indicators included in our study were derived from census super-output areas, smaller than either the London electoral wards used by Congdon or the 633 parliamentary constituents across Britain used by Whitley et al. ${ }^{3,4}$ This was considered appropriate, on the assumption that the smaller the population encompassed by an area the more homogeneous it is likely to be.

Finally, research related to area-level effects on health is dependent on the measures of deprivation and fragmentation. As Congdon has stated, ${ }^{33}$ deprivation measures should ideally include income and indicators of fragmentation should include measures of community ties, but in practice we are generally limited to data available from the census. It is possible that the measures of social fragmentation or deprivation, which worked so well in the ecological studies in Great Britain, are not so applicable in Northern Ireland, which contains only one city of note (Belfast) and is more rural in comparison with the rest of the UK. However, a comparison of the constituent elements of the fragmentation measure at the time of the census showed a significant difference only for population turnover (Northern Ireland 9.3\%, England \& Wales 12.2\%), ${ }^{34,35}$ and ecological studies in Northern Ireland ${ }^{36}$ have replicated the associations between deprivation and health found in equivalent studies in the rest of the UK. ${ }^{37,38}$

\section{Policy implications}

Most ecological studies have found a strong link between area factors and mental health and risk of suicide, and have concluded that appropriate health-promoting and protection measures should be directed towards areas at risk as well as towards individuals at risk. However, the conclusions from studies such as this, which control for both individual and area-level factors, are that most - if not all - of the variation between areas arises because of differences between the populations within these areas. This suggests that policies targeted at area-level factors are unlikely to have a material impact on suicide rates.

Dermot O'Reilly, MD, Michael Rosato, MSC, Sheelah Connolly, MSC, Chris Cardwell, PhD, Epidemiology and Public Health, Centre for Clinical and Population Sciences, Queen's University, Belfast

Correspondence: Dermot O'Reilly, Epidemiology and Public Health, Centre for Clinical and Population Sciences, Mulhouse, Royal Victoria Hospital, Grosvenor Road, Belfast BT12 6BJ, UK. Email: d.oreilly@qub.ac.uk

First received 14 May 2007, final revision 6 Aug 2007, accepted 8 Oct 2007

\section{References}

1 Jarvis $F$, Ferrence G, Whitehead $P$, Johnson FG. The ecology of self-injury: a multivariate approach. Suicide Life Threat Behav 1982; 12: 90-102.

2 Wing J. Epidemiologically Based Mental Health Needs Assessments: Review of Research on Psychiatric Disorders (ICD10, F2-F6). Chadwick Healey, 1982.

3 Congdon P. Suicide and parasuicide in London: a small-area study. Urban Stud 1996; 33: 137-58.

4 Whitley E, Gunnell D, Dorling D, Davey Smith G. Ecological study of social fragmentation, poverty, and suicide. BMJ 1999; 319: 1034-7.

5 O'Reilly D, Rosato M, Connolly S. Unlinked vital events in census based longitudinal studies can bias subsequent analysis. J Clin Epidemiol 2007; (in press).

6 World Health Organization. International Statistical Classification of Diseases and Related Health Problems (ICD-10). WHO, 1992.

7 Rose D, Pevalin D (eds). A Researcher's Guide to the National Statistics Socio-economic Classification. Sage, 2002.

8 Moser K, Fox A, Jones D. Unemployment and mortality in the OPCS Longitudinal Study. Lancet 1984; 2: 1324-9.

9 Iversen L, Andersen O, Andersen P, Christoffersen K, Keiding N. Unemployment and mortality in Denmark, 1970-80. BMJ 1987; 295: 879-84.

10 Martikainen P. Unemployment and mortality amongst Finnish men, 1981-5. BMJ 1990; 301: 407-11.

11 Gunnell D, Peters T, Kammerling M, Brooks J. The relation between parasuicide, suicide, psychiatric admissions, and socioeconomic deprivation BMJ 1995; 311: 226-30.

12 Northern Ireland Statistics and Research Agency. Northern Ireland Multiple Deprivation Measure 2005. NISRA, 2005.

13 Liang KY, Zeger SL. Longitudinal data analysis using generalized linear models. Biometrika 1986; 73: 13-22.

14 Hosmer DW, Lemeshow S. Applied Logistic Regression (2nd edn). Wiley, 2000.

15 Gunnell D, Shepperd M, Evans M. Are recent changes in deliberate self-harm associated with changes in socio-economic conditions? An ecological analysis of patterns of deliberate self-harm in Bristol 1972-3 and 1995-6. Psychol Med 2000; 30: 1197-203.

16 Allardyce J, Gilmour H, Atkinson J, Rapson T, Bishop J, Mccreadie R. Social fragmentation, deprivation and urbanicity: relation to first-admission rates for psychoses. Br J Psychiatry 2005; 187: 401-6.

17 Almog M, Curtis S, Copeland A, Congdon P. Geographical variation in acute psychiatric admissions within New York City 1990-2000: growing inequalities in service use? Soc Sci Med 2004; 59: 361-76.

18 Curtis S, Copeland A, Fagg J, Congdon P, Almog M, Fitzpatrick J. The ecological relationship between deprivation, social isolation and rates of hospital admission for acute psychiatric care: a comparison of London and New York City. Health Place 2006; 12: 19-37.

19 Hempstead K. The geography of self-injury: spatial patterns in attempted and completed suicide. Soc Sci Med 2006; 62: 3189-96.

20 Fernquist $R$, Cutright $P$. Societal integration and age-standardised suicide rates in 21 developed countries, 1955-1989. Soc SCi Res 1998; 27: 109-27.

21 Reijneveld S, Schene A. Higher prevalence of mental disorders in socioeconomically deprived urban areas in The Netherlands: community or personal disadvantage? J Epidemiol Community Health 1998; 52: 2-7.

22 Weich S, Twigg L, Holt G, Lewis G, Jones K. Contextual risk factors for the common mental disorders in Britain: a multilevel investigation of the effects of place. J Epidemiol Community Health 2003; 57: 616-21. 
23 Skapinakis P, Lewis G, Araya R, Jones K, Williams G. Mental health inequalities in Wales, UK: multi-level investigation of the effect of area deprivation. Br J Psychiatry 2005; 186: 417-22.

24 Hawton K, Harriss L, Hodder K, Simkin S, Gunnell D. The influence of the economic and social environment on deliberate self-harm and suicide: an ecological and person-based study. Psychol Med 2001; 31: 827-36.

25 Johnston A, Cooper J, Webb R, Kapur N. Individual- and area-level predictors of self-harm repetition. Br J Psychiatry 2006; 189: 416-21.

26 Qin $\mathrm{P}$, Agerbo $E$, Bo Mortensen P. Suicide risk in relation to socioeconomic, demographic, psychiatric, and familial factors: a national register-based study of all suicides in Denmark, 1981-1997. Am J Psychiatry 2003; 160: 765-72.

27 Agerbo E, Sterne J, Gunnell D. Combining individual and ecological data to determine compositional and contextual socio-economic risk factors for suicide. Soc Sci Med 2007; 64: 451-61.

28 Martikainen P, Mäki N, Blomgren J. The effects of area and individual social characteristics on suicide risk: a multilevel study of relative contribution and effect modification. Eur J Popul 2004; 20: 323-50.

29 Lewis G, Sloggett A. Suicide, deprivation, and unemployment: record linkage study. BMJ 1998; 317: 1283-6.

30 Weich S, Lewis G. Poverty, unemployment, and common mental disorders: population based cohort study. BMJ 1998; 317: 115-19.
31 Kunce $M$, Anderson A. The impact of socioeconomic factors on state suicide rates: a methodological note. Urban Stud 2002; 39: 155-62.

32 Durkheim E. Suicide: A Study in Sociology (transl. Spalding J, Simpson G). Routledge \& Kegan Paul, 1952

33 Congdon P. Commentary: contextual effects: index construction and technique. Int J Epidemiol 2004; 33: 741-2.

34 Northern Ireland Statistics and Research Agency. Northern Ireland 2001 Output. http://www.nisra.gov.uk/census/census2001output/index.htm.

35 Office for National Statistics. Census 2001. http://www.statistics.gov.uk/ census2001/census2001.asp.

36 Stringer P. Health Inequalities, Religious Affiliation and Urban-rural Status: Report to the Department of Health and Social Services (NI). Northern Ireland DHSS, 1992.

37 Townsend $\mathrm{P}$, Philimore $\mathrm{P}$, Beattie A. Health and Inequalities in the North. Croom Helm, 1988

38 Carstairs V , Morris R. Deprivation and Health in Scotland. Aberdeen University Press, 1991.

39 O'Reilly G, O'Reilly D, Rosato M, Connolly S. Urban and rural variations in morbidity and mortality in Northern Ireland. BMC Public Health 2007; 7: 123 (http://www.biomedcentral.com/1471-2458/7/123).

\section{Word pictures of depression: tearfulness}

\section{sharon Mcconville}

Shortly after my admission to hospital, I wrote:

'Today, tears came. They poured out of me, not like little wavelets brimming over the edge of an overfilled swimming pool, but in a great gush, as if the reservoir of emotion and despair which is my soul had swelled to burst its dams. Deep, guttural sobs racked my body. I was in the foyer of the cancer centre when it happened. It was the sight of [ . . . ] walking towards me with open arms, ready to enfold me in a warm embrace, which precipitated the flow. As I buried my head in her soft coat collar, her lips kissed my hair. She supported me as we walked towards two adjacent chairs, where we sat down, wrapped in one another's arms, me crying uncontrollably; she stroking my head. I was aware of seemingly hundreds of pairs of eyes fixed upon me. In a sense, it was heartening to know that such a sight is not uncommon in the cancer centre. I have seen many people crying there before myself. However as people around me whispered; "That poor girl. She must have lost somebody," or "She must be ill. Look how thin she is. Maybe she's had bad news," I felt a pang of guilt. After all, I was only depressed. Then I realised - dare I say it - that I honestly believed that a death or diagnosis of cancer would actually have been easier to deal with.

I continued to cry all afternoon. I cried in the nurses' station, surrounded by staff, including a rather bemused-looking dietitian who had come to see me and whom I later realised had actually been at school with me, albeit a couple of years ahead. I cried in the interview room, as I waited to speak to this dietitian, who ultimately decided to defer the discussion until a later date. I cried in the dormitory, where I desperately tried to collect myself by sipping at a cup of herbal tea which one of the nurses had prepared for me. I cried in the day room as soon as [ . . . ] appeared to visit me. I cried in the office belonging to [my lead nurse] when he decided that we needed to have a chat later in the afternoon. I cried in my bed. I cried in the corridor. I cried in the toilet. I finished up exhausted and suffering from frightening palpitations. My eyes were burning, the lids rasping against them like sandpaper, and my head was pounding. At the same time, I felt some measure of relief: a relief akin to that experienced by a gentleman with prostatism whose bladder has just been catheterised, or that felt when a swollen, engorged boil is lanced and the pus can drain freely from it.

Aside from relief, however, I felt something else. It was as if something momentous had happened to me. I felt as I had been suddenly stripped, my vulnerability laid bare. I imagined myself as one of those plasticated bodies in the anatomy exhibition which has recently caused such controversy in the media, my skin peeled back to expose my raw flesh and sinews. It was a scary, dizzying sort of a feeling. I was unsure quite what it meant.' 